\title{
Acute myocarditis associated with the Pfizer/BioNTech vaccine
}

\author{
Monika Shumkova', Dobrin Vassilev', Kiril Karamfiloff', Raya Ivanova', Kristina Stoyanova', \\ Teodora Yaneva-Sirakova', Robert J Gil ${ }^{2}$ \\ 'Department of Cardiology, Alexandrovska University Hospital, Faculty of Medicine, Medical University of Sofia, Sofia, Bulgaria \\ ${ }^{2}$ Mossakowski Medical Research Center, Polish Academy of Sciences, Poland Department of Invasive Cardiology, Central Clinical Hospital of the Ministry \\ of the Interior, Warszawa, Poland
}

\author{
Correspondence to: \\ Assist. Prof. Monika Shumkova, \\ MD, \\ Department of Cardiology, \\ Alexandrovska University \\ Hospital, \\ Faculty of Medicine, Medical \\ University of Sofia, \\ Sveti Georgi Sofiyski 1 , \\ 1431, Sofia, Bulgaria, \\ phone: +359883475726 \\ e-mail: \\ monika_shumkova@yahoo.com \\ Copyright by the Author(s), 2021 \\ Kardiol Pol. 2021; \\ 79 (11): 1282-1283; \\ DOI: $10.33963 /$ KP.a2021.0095 \\ Received: \\ August 5, 2021 \\ Revision accepted: \\ August 23, 2021 \\ Published online: \\ August 23, 2021
}

A 23-year-old man without any medical history presented in the Emergency Department with fever, shortness of breath, and progressive chest pain exacerbated by deep inspiration and supine position. The symptoms started one day after receiving the second dose of the Pfizer/BioNTech vaccine. After the first dose, he did not have any side effects. He had not been infected with SARS-CoV-2 before.

The patient's electrocardiogram (Figure $1 \mathrm{~A})$ showed ST-elevation in inferior and V4-V6 leads. Laboratory tests revealed rising high sensitive troponin $\mathrm{T}$ (hs-TnT) $-0.190 \mathrm{ng} / \mathrm{ml}$, two hours later $-0.370 \mathrm{ng} / \mathrm{ml}$ (normal 0.00-0.014), creatine kinase (CK) $-289 \mathrm{U} / \mathrm{l}, 403 \mathrm{U} / \mathrm{I}$ (normal $<190 \mathrm{U} / \mathrm{l})$, and $\mathrm{MB}$ fraction - $31 \mathrm{U} / \mathrm{l}, 82 \mathrm{U} / \mathrm{l}$ (normal <25 U/l), increased B-type natriuretic peptide, and C-reactive protein - $79 \mathrm{mg} / \mathrm{l}$ (normal 0-5 mg/l). A COVID-19 infection and common viral serology were ruled out. Autoimmune disorders were unlikely.

Echocardiography (Figure 1B) demonstrated borderline left ventricular ejection fraction (LVEF) with hypokinesis of the anterior, inferior, and lateral walls.

After noninvasive tests, emergency coronary angiography was performed and ruled out acute coronary syndrome. Because of the local protocol, during the invasive procedure left ventriculography was carried out (Supplementary material, Figure S1). Then, the patient was referred for cardiac magnetic resonance imaging (CMRI) to define the cause of left ventricular damage (Figure 1D-F).

Given the initial clinical presentation, the time of vaccination, laboratory and imaging tests, our diagnosis was myocarditis after the second dose of the Pfizer/BioNTech vaccine.
After initial therapy with acetylsalicylic acid, methylprednisolone, and antibiotics, the symptoms were relieved. Troponin and C-reactive protein levels dropped to the reference range, and the electrocardiogram showed complete ST-segment resolution with negative T-waves. Before hospital discharge on day 6, echocardiography demonstrated improvement in wall motion and ejection fraction (Figure 1C).

At the follow-up visit in the first week, echocardiography demonstrated LVEF of $58 \%$.

Several cases of acute myocarditis after the mRNA vaccine have been reported [1, 2]. Echocardiography is useful to exclude other causes of heart disease. The preferable diagnostic tool is CMRI.T2-weighted images detect myocardial edema. T1-weighted images show hyperemia and early capillary leakage in early gadolinium enhancement, necrosis and fibrosis based on late gadolinium enhancement [5]. CMRI is an accurate diagnostic test for acute and chronic myocarditis. In our case, CMRI imaging abnormalities fulfill the Lake Louise criteria [4]. Coronary angiography helped us to exclude coronary artery disease in the presence of typical chest pain, ST-elevation, and high levels of cardiac biomarkers (CK, CK-MB, hs-TnT).

Cardiovascular involvement in the SARSCoV-2 infection is associated with poor prognosis even in young adults. Post-vaccine myocarditis is rare, and, in the majority of cases, complete recovery is observed. Most of them have been reported in males, young adults, or adolescents, most commonly after the second dose [3]. Treatment is as usual, as per recommendations for myocarditis [5]. Corticosteroids may decrease specific auto- 

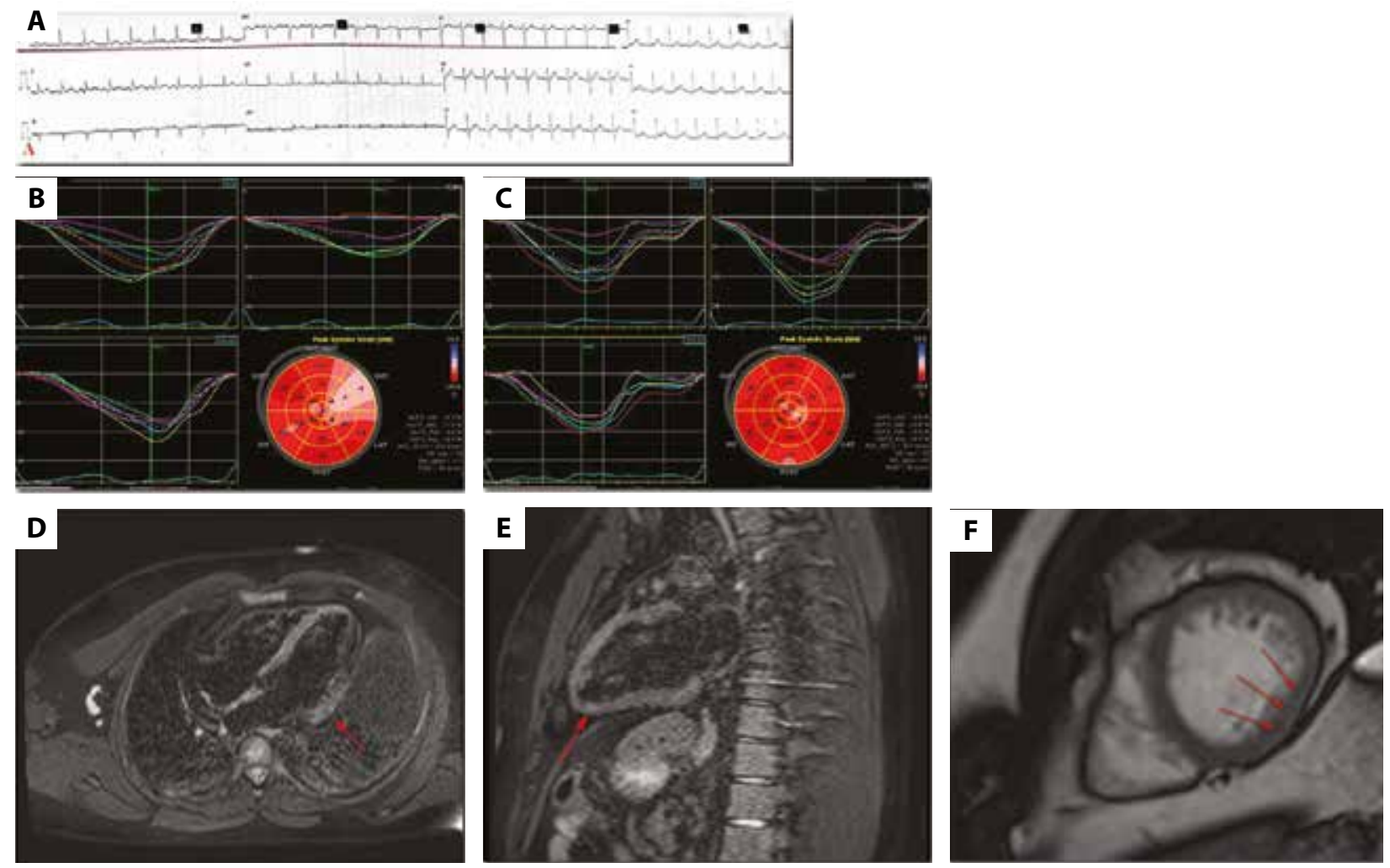

Figure 1. A. Electrocardiogram $-1^{\text {st }}$ day. Sinus rhythm, normal axis deviation, heart rate 100/min, ST-elevation in I, II, aVL, aVF,

V4-V6 leads. B. Echocardiography on $1^{\text {st }}$ day. "Bull's-eye" map of global left ventricle longitudinal strain measurements. Impaired left ventricle longitudinal strain in anterolateral and apical segments. Average LV global longitudinal strain, GLS" $-10.7 \%$ ". Ejection fraction - $45 \%$.

C. Echocardiography on $3^{\text {rd }}$ day. "Bull's-eye" map of global left ventricle longitudinal strain measurements. Reduced longitudinal left ventricle function in apical segments. Average LV global longitudinal strain, GLS "-14.4\%". Ejection fraction - 52\%. D-F. Cardiac magnetic resonance image shows borderline LVEF - 47\% with normal right heart chambers. D, E. Long-axis view, T2 weighted reveal increased signal intensity in basal segments of the LV free wall and apical segments, which indicates interstitial edema (the red arrow). F. Short axis view - T1-weighted imaging series demonstrating increased late gadolinium enhancement with subepicardial distribution in the basal segments of free LV wall, apical, lateral (the red arrows), and inferior wall

Abbreviations: GLS, global longitudinal strain; LV, left ventricle; LVEF, left ventricular ejection fraction

immune responses, but they should be restricted to LV recovery and symptoms resolution [1].

Undoubtedly the benefits of vaccines outweigh the risks. Patients who had suffered post-vaccine myocarditis must be under close monitoring for further cardiovascular complications.

\section{Supplementary material}

Supplementary material is available at https://journals. viamedica.pl/kardiologia_polska.

\section{Article information}

Conflict of interests: None declared.

Open access: This article is available in open access under Creative Common Attribution-Non-Commercial-No Derivatives 4.0 International (CC BY-NC-ND 4.0) license, allowing to download articles and share them with others as long as they credit the authors and the publisher, but without permission to change them in any way or use them commercially. For commercial use, please contact the journal office at kardiologiapolska@ptkardio.pl.
How to cite: Shumkova M, Vassilev D, Karamfiloff K, et al. Acute myocarditis associated with Pfizer/BioNTech vaccine. Kardiol Pol. 2021; 79(11): 1282-1283, doi: 10.33963/KP.a2021.0095.

\section{REFERENCES}

1. Larson KF,Ammirati E, AdlerED, etal.Myocarditis after bnt162b2 andmRNA1273 vaccination. Circulation. 2021; 144(6): 506-508, doi: 10.1161/CIRCULATIONAHA.121.055913, indexed in Pubmed: 34133884.

2. Montgomery J, Ryan M, Engler R, et al. Myocarditis following immunization with mRNA COVID-19 vaccines in members of the US military. JAMA Cardiol. 2021 [Epub ahead of print], doi: 10.1001/jamacardio.2021.2833, indexed in Pubmed: 34185045.

3. FoCDC. COVID-19VaST Work Group Technical Report-May 17, 2021. Advisory Committee on Immunization Practices (ACIP). https://www.cdc. gov/vaccines/acip/work-groups-vast/technical-report-2021-05-17.html (August 4, 2021).

4. Pan JA, Lee YJ, Salerno M. Diagnostic performance of extracellular volume, native $\mathrm{T} 1$, and $\mathrm{T} 2$ mapping versus Lake Louise criteria by cardiac magnetic resonance for detection of acute myocarditis: a meta-analysis. Circ Cardiovasc Imaging. 2018; 11(7): e007598, doi: 10.1161/CIRCIMAGING.118.007598, indexed in Pubmed: 30012826.

5. Ammirati E, Frigerio M, Adler ED, et al. Management of acute myocarditis and chronic inflammatory cardiomyopathy: an expert consensus docu- 